\title{
Patients very satisfied with implant supported dentures
}

\author{
How happy are patients with their implant-retained overdentures?
}

\begin{abstract}
MacEntee MI, Walton JN, Glick N. A clinical trial of patient satisfaction and prosthodontic needs with ball and bar attachments for implant-retained complete overdentures: threeyear results. J Prosthet Dent 2005; 93:28-37

Design This was a randomised clinical trial (RCT).

Intervention Subjects were randomly assigned to one of four treatment groups. These used either ball-spring or bar-clip attachments for mandibular dentures, using an acrylic base, with or without a cast metal alloy framework. Study participants were asked to complete visual analogue scales (VAS) to self-report on satisfaction with their conventional complete dentures at baseline and with implant-supported dentures (ISP) at 1 month, 1 year and 2 years following placement.
\end{abstract}

Outcome measure The number of adjustments and repairs to implant-supported dentures and associated costs were recorded over the period of the study. Median satisfaction scores were calculated for each of the seven components measured by the VAS.

Results The presence or absence of a cast metal framework had no impact on either denture maintenance or self-reported satisfaction so data were considered to relate to two treatment groups only, ie, the ball-spring or bar-clip attachment groups. Thirty-four subjects were followed for 3 years in each of the two groups. Median satisfaction with mandibular dentures rose from 13 (out of 100) at baseline for both groups to 93 for the bar-clip group and 94 for the ball-spring group 1 month after placement. VAS scores improved significantly for six out of seven components of "satisfaction" for the bar-clip group and for all seven of the seven components for the ball-spring group, after 1 month. Median overall satisfaction did not decline to any significant extent over 2 years. Significantly more repairs were required in the ball-spring group than the bar-clip group.

Conclusions Subjects were equally and very satisfied with their impact-retained overdentures, whether bar-clip or ball-spring attachment. The latter design, however, required substantially more repairs.

\section{Commentary}

Currently all evaluations of the success of the process of osseointegration seem unequivocal, a plethora of literature confirming the long-term survival of osseointegrated implants. There is, however, a paucity of evidence from RCT to support the routine use of implantretained prostheses in edentulous patients. From a clinical perspective, there is an inherent attraction in using implants to retain a prosthesis, particularly in the mandible. Fund providers and patients alike nevertheless need to be convinced that substantial benefits accrue from this procedure before committing the significant extra funds for treatment and, indeed, undergoing surgical procedures to place implants.

A group at McGill University, Montreal, Canada, have published reports from a number of $\mathrm{RCT}^{1-3}$; these showed that patients receiving implant-retained overdentures report substantial improvement on more outcomes than patients who received conventional treat-

Address for correspondence: Dr Michael MacEntee, Department of Oral Health Sciences, Faculty of Dentistry, University of British Columbia, 2199 Wesbrook Mall, Vancouver, British Columbia, Canada. E-mail: macentee@interchange.ubc.ca. ment. The periods of follow-up were relatively short, so the evidence provided here by MacEntee et al. is timely.

The present study differs from the previous ones in that there are no conventional denture control groups. In this RCT, 100 edentulous patients were randomised into one of four treatment groups (either ball-retained mandibular overdenture with or without reinforced framework, or bar-clip retained mandibular overdenture with or without reinforced framework), and between-group comparisons are made. The primary outcomes of interest are patient-rated satisfaction and maintenance requirements. The authors based their sample size on detecting, "a differential of 25 percentage points or more between the proportions requiring repairs in the two attachment groups," but details of the power calculation and rationale for it are vague. It is also unclear whether this power calculation was appropriate for detecting differences in VAS.

In addition, the authors appear not to have adjusted the VAS outcomes for multiple comparisons. Consequently, the data need to be interpreted cautiously. Despite these caveats, the follow-up time is 3 years for 68 subjects, and long-term satisfaction with implantretained overdentures is confirmed. Eleven subjects were lost to follow-up, and a further 19 had not completed 3 years in the study at the time of publication. There is nothing to suggest that this undermined the conclusions of the study. Satisfaction at 2 years is comparable with VAS scores at 1 month post-insertion, and this finding contrasts with studies of conventional dentures. The mode of the attachment of the overdenture does not appear to significantly influence satisfaction.

A common problem with overdentures is the relatively high maintenance requirement, and an important finding from the study is that ball-retained overdentures require much more maintenance than do bar-clip retained overdentures. This may influence clinical practice in general, and is perhaps the most important outcome from this study.

\section{Practice point}

- Patients are highly satisfied with implant-supported dentures at 2 years, although ball-retained overdentures require more maintenance than bar-clip retained overdentures.

\section{Finbarr Allen}

Department of Restorative Dentistry, University Dental School and Hospital, Wilton, Cork, Ireland

1. Heydecke G, Thomason JM, Lund JP, Feine JS. The impact of conventional and implant supported prostheses on social and sexual activities in edentulous adults Results from a randomized trial 2 months after treatment. J Dent. 2005;33:649-57.

2. Heydecke G, Penrod JR, Takanashi Y, Lund JP, Feine JS, Thomason JM. Costeffectiveness of mandibular two-implant overdentures and conventional dentures in the edentulous elderly. J Dent Res. 2005; 84(9):794-9.

3. Awad MA, Lund JP, Shapiro SH, Locker D, Klemetti E, Chehade A, et al. Oral health status and treatment satisfaction with mandibular implant overdentures and conventional dentures: a randomized clinical trial in a senior population. Int J Prosthodont. $2003 ; 16(4): 390-6$.

Evidence-Based Dentistry (2006) 7, 34.

doi:10.1038/sj.ebd.6400397 